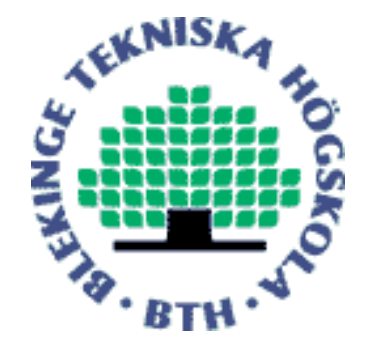

Copyright (C) 2013 IEEE.

Citation for the published paper:

Empirical Software Engineering Research with Industry: Top 10 Challenges

Claes Wohlin

Proceedings of the First International Workshop on Conducting Empirical Studies in Industry (CESI)

2013 San Francisco, USA

This material is posted here with permission of the IEEE. Such permission of the IEEE does not in any way imply IEEE endorsement of any of BTH's products or services Internal or personal use of this material is permitted. However, permission to reprint/republish this material for advertising or promotional purposes or for creating new collective works for resale or redistribution must be obtained from the IEEE by sending a blank email message to pubs-permissions@iee.org.

By choosing to view this document, you agree to all provisions of the copyright laws protecting it. 


\title{
Empirical Software Engineering Research with Industry: Top 10 Challenges
}

\author{
Claes Wohlin \\ School of Computing \\ Blekinge Institute of Technology \\ Karlskrona, Sweden \\ Claes.Wohlin@bth.se
}

\begin{abstract}
Software engineering research can be done in many ways, in particular it can be done in different ways when it comes to working with industry. This paper presents a list of top 10 challenges to work with industry based on our experience from working with industry in a very close collaboration with continuous exchange of knowledge and information. The top 10 list is based on a large number of research projects and empirical studies conducted with industrial research partners since 1983. It is concluded that close collaboration is a long-term undertaking and a large investment. The importance of addressing the top 10 challenges is stressed, since they form the basis for a long-term sustainable and successful collaboration between industry and academia.
\end{abstract}

Index Terms-Industry collaboration, empirical studies, industry challenges.

\section{INTRODUCTION}

Research together with industry is very much a mindset. Researchers must be aware of the goals of any industrial partner and the reason for them to participate in the collaboration. Industrial partners are normally not there to help a researcher with his or her research. They have an agenda of their own, and successful collaboration can only be conducted once there is a joint understanding of roles and goals.

It is actually not about doing studies "in industry"; it is about doing studies "with industry". This is a key issue when it comes to the mindset, which is not only a matter for the researcher, but also for the industrial collaborators who must understand and respect the difference between a researcher and a consultant. Industry must understand and accept that researchers can address areas with industrial challenges; researchers do not solve short-term problems.

An additional problem is the concept of "technology transfer", which implies that a research result is transferred from research to industry. However, collaborative research and in particular empirical studies with industry is much more knowledge exchange than technology transfer. The concept of technology transfer implies that researchers have the solution and only should move it into industry. This is far from true, in particular in such a discipline as software engineering, which is really a design science.

Based on 30 years of experience from software engineering (25 years in academic research and 5 years working with software development in industry), the paper presents experiences from conducting empirical studies with industry in very close collaboration. The experiences are packaged into a list of the top 10 challenges to succeed in close collaboration between industry and academia, when it comes to empirical software engineering research.

The remainder of the paper is outlined as follows. Section II presents some related work. In Section III, our model for collaborating between industry and academia is presented briefly. Section IV describes the top 10 challenges in industryacademia collaboration. The paper is concluded in Section V.

\section{RELATED WORK}

The need to collaborate between industry and academia has been acknowledged in software engineering for along time, and also implemented in a systematic way as exemplified with the Software Engineering Laboratory (SEL) [1]. SEL is one good example of a successful collaboration, but it also showed the importance of committed individuals. Others have also contributed to the continuous dialogue and discussion about the need for collaboration and partnership between industry and academia [2], [3] and [4]. Furthermore, the need for industrial relevance in academia, and in particular in education [5], has been highlighted. Another line of work has been to use students as subjects in controlled experiments, for example, to evaluate specific reasonably isolated parts of software development as conducted in [6]. However, the challenge still remains of how to transfer findings from student studies to industry practice.

There is obviously a great need for collaboration, but still it does not seem to be the case in general. The need for a credible empirical basis of software engineering has been on the agenda for 20 years [7]. An empirically driven model for working with industry was presented in [8], and hence experiences of how it can be done are available. This model represents a very close collaboration between industry and academia. Despite these insights as well as documentation of success factors for collaboration between industry and academia [9] and [10], it is still hard to build a sustainable long-term research collaboration between industry and academia.

The lessons from literature point to systemic problems in the academic system. The academic reward system does not really acknowledge industrial collaboration. The reward system is very much driven by publications, research funding and graduation of students. Thus, it is understandable that there is a 
gap, even if most software engineering researchers acknowledge the need for collaboration between industry and academia. As a first step to address this gap, this paper provides a top 10 list of challenges to address to ensure a successful collaboration between industry and academia. The list is based on a compilation of experiences from collaborating with industry over the years, including large international companies such as Ericsson, Sony and ABB.

\section{COLLABORATIVE MODEL}

The top ten challenges for conducting research together with industry are based on or experience in working very closely with industry. It entails a mutual knowledge exchange between industry and academia. It is not about transferring results from research to industry; it is a joint venture with mutual learning. The researcher and her or his industrial partners form a joint team to address an industrial challenge. The research is conducted with close and regular contacts and discussions with the industrial partners. Results are continuously transferred and evaluated in industrial use, which informs the continuation of the research. Publications are sometimes written jointly with industry representatives, and industry partners read and approve that the descriptions of the companies are correct and formulated in such a way that it does not reflect badly on the company. The model is illustrated in Fig. 1.

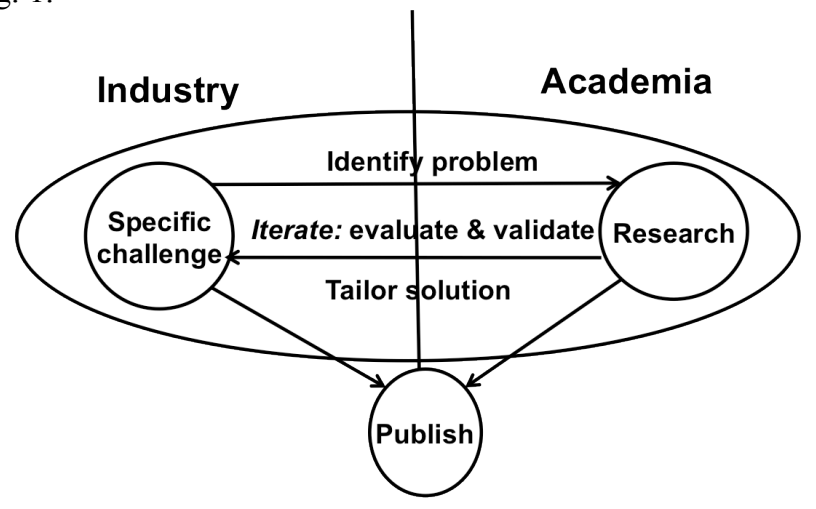

Fig. 1. Research as one team

The research approach is based on design science as summarized in [11], and the actual empirical studies often include interviews, archival analysis and case studies at the industry partners as described in [8]. To really be able to do empirical studies with industry, the research has to be conducted in close collaboration as illustrated in Fig. 1. It is of course possible to conduct individual studies in industry if having good industrial contacts. However, in our experience, the most rewarding collaboration for both industry and academia come with a long-term and continuous collaboration.

A prerequisite to succeed in the close collaboration is that the researchers are accepted and trusted to the level that they preferably have access to the premises, computer systems, software and databases of the industry partners. This of course requires signing appropriate confidentiality agreements.

\section{TOP 10 CHALLENGES}

To truly conduct empirical research studies in software engineering with industry in a long-term relationship, it is here assumed that research ought to be conducted in very close collaboration between industry and academia. It is of course possible to conduct individual studies at one specific company and then not work with them again. However, here it is assumed that there is a wish to have a long-term relationship whether being a series of individual studies over time or continuous collaboration. In this context, a list of ten key challenges to master has been compiled based on our experiences.

The ten challenges presented here are based on our long experience from working with industry and conducting joint empirical research studies with different companies. The challenges to master have not been ranked internally, since it does not make sense to only focus on some of them; all ten must be addressed in parallel to increase the chances for successful collaboration between industry and academia.

The challenges have been divide into four sub-groups:

- General - This group relates to challenges to the general relationship between industry and academia.

- Industry - Challenges in this group concern specific issues to be addressed at the industry side of the collaboration.

- Academia - In a similar way as for industry, there are some specific challenges related to academia.

- $\quad$ Research - The actual conduct of the research comes with some challenges too, and they belong to this subgroup.

The challenges within each sub-group are described as follows:

General

1. Trust and respect - All parties involved must trust and respect each other. This is not only decided; in our experience these have to be earned through meetings and discussions. Academia has to acknowledge and respect the experiences and expertise of their industry partners in developing industrial software-intensive systems, and industry has to respect the deeper knowledge coming with being a researcher. The mutual benefits of having different strengths must become clear to the individuals involved. Trust comes with working together and spending time together. It comes faster with good references from other people that you trust yourself.

2. Roles and their goals - It is obvious that industry and academia have different roles, but different people in the respective organizations have different roles too. For example, a senior researcher has a different role and hence different goals than a PhD student. The main goal of a $\mathrm{PhD}$ student should be her or his thesis, while a senior researcher may have other goals. In a similar way, people in industry have different roles and hence responsibilities and goals. These differences must be communicated and fully understood by all individuals 
involved. Academia must accept that industry deadlines and budgets override most other issues. The challenge is to find ways of working within these boundaries, and in the problems it may create, for example, cancellations of meetings with short notice. In summary, each individual must try to understand the roles, responsibilities and goals of the other people involved in the collaboration.

3. Knowledge exchange and not technology transfer - It must be understood that knowledge has to be exchanged. Academia must not assume that they can transfer a research result directly. They must understand the industrial context. This means that industry must provide quite some access to researchers to ensure that results from research actually fits into their context. Without this mutual exchange close collaboration is bound to fail.

\section{Industry}

4. Management - It is insufficient to only have good contacts with specific individuals at a company. It is a necessary requirement to have good contacts, but insufficient. If to succeed in a long-term and mutually beneficial collaboration between industry and academia, there must be management commitment. The commitment must come from the manager actually being responsible for the resources to be used in the collaboration, preferably with support from higher-level management.

5. Champion - A champion is always needed; it is the main driver of the collaboration on the industry-side. As the word "champion" implies, it must be a person who is committed to facilitate and contribute to a successful collaboration. A person cannot be assigned to be the champion. It will simply not work, either the person wants to be a champion or not.

\section{Academia}

6. Social skills - Collaboration with industry and joint empirical studies imply that it is primarily researchers (or students) that go to industry. This is the case since the objective is most often to conduct studies in relation to: actual development at the company, access to product and project artifacts or access to databases such as databases for defect reports and change requests. In most cases, these have to be studied at the company premises, due to reasons of confidentiality. Thus, the researcher becomes the visitor. In such a situation, it is very important that the researcher has good social skills. The researchers must feel comfortable to walk around and knock on doors, and to go to joint lunches and coffee breaks. Physical presence and communication help in building trust and respect, and is almost a prerequisite for a successful collaboration between industry and academia.

7. Commitment to company needs - The primary reason for most companies to collaborate is that they believe (or hope) that academia can help them. They may have secondary reasons such as creating a basis for recruitment or in general wanting to have a good relationship with a university close by. However, the main reason is most often that they have some challenges where they believe an external person used to critical thinking and coming from a different perspective could help. Thus, the company has expectations. This implies that researchers must be aware of the expectations and be committed to deliver according to them not to disappoint their industry partners.

\section{Research}

8. Software engineering as a design science - Once accepting that the collaboration must be based on mutual exchange of knowledge (see Fig. 1) then the challenges of actually making it work becomes obvious. The starting point is most often a problem or an industrial challenge. However, it is important to not only accept the problem description given by one person. Preferably, the researcher should be able to study and evaluate the problem area to better pinpoint the actual problem. For example, a company informed us that they had a problem with prioritizing requirements, and they wanted to collaborate on this issue. When the problem was analyzed, it turned out that the first step was to make the requirements comparable. Some requirements were described on a very high level and others were very detailed, and hence actual prioritization between them was indeed impossible. The actual research ended up being focused on a Requirements Abstraction Model [12] and [13]. The model was evaluated empirically in several steps including a student experiment and industry cases studies according to our way of working as described in [8]. The conduct of these steps is a challenge and industry interest and commitment have to be kept throughout the research.

9. Integrate into daily work - A key issue to keep industry interest and commitment is to tie the research into the daily work at any industry partner. This is the only way in our experience to ensure success in the joint venture. As soon as the research and the empirical studies are not related to the core business and its challenges of the company, then the risk of failing increases tremendously. Thus, it is important to integrate tightly into your industry partner; it is preferable to become embedded into the industrial environment. It also means that regular feedback of progress and results need to be reported, both to people participating in, for example, different empirical studies and management. Having a reference or steering group that has regular meetings, for example, monthly meetings where progress, results and plans are discussed and decisions are taken addresses the need for feedback cycles.

10. Ability to combine quantitative and qualitative inputTo conduct empirical studies with industry most often include obtaining both quantitative and qualitative data. Thus, the researcher must be able to conduct a 
combined analysis of different types of data. For example, defect data and complexity measures may provide some perceived patterns in relation to faultproneness of different components of the software system, but the patterns may very well relate to the experience of the developers and change in personnel. Only collecting the defect data and run tools calculating different complexity measures does not capture the latter. The researcher must interview people and understand how the qualitative information could be combined with the quantitative data obtained. The researcher must be able to cope with this type of analysis situations.

There are other challenges to collaborate between industry and academia, but based on our experiences the top 10 challenges are the ones listed above. They must be addressed explicitly to ensure that empirical studies with industry and research collaboration between industry and academia in software engineering more generally are successful. Collaboration is only successful when both industry and academia perceive that they have reached their goals with the collaboration. Furthermore, success builds future successes, and hence failure is not really an option, since it is very difficult to regain confidence and trust to launch new collaborations based on failure.

\section{CONCLUSIONS}

Conducting research and empirical studies with industry requires a lot of work, but it is mostly very rewarding. It provides researchers with access to industrial developers, real artifacts and data from industry projects. In our experience, it is very much a matter of building a long-term sustainable relationship with mutual trust and respect. Successful collaboration between industry and academia is very much a mindset and a joint willingness to succeed.

Based on our experiences, a top 10 list of challenges has been formulated. They challenges may be divided into four areas: general, industry, academia and research. The challenges in these four areas are:

General: 1) trust and respect, 2) roles and their goals, and 3) knowledge exchange and not technology transfer,

Industry: 4) management, and 5) champion,

Academia: 6) social skills, and 7) commitment to industry needs,

General: 8) software engineering as a design science, 9) integrate into daily work, and 10) ability to combine quantitative and qualitative input.

These are not internally ranked, since all of them have to be in place to achieve a close and mutually beneficial collaboration. This is the case for software engineering research in general, but in particular it is crucial for conducting empirical studies with industry.

\section{ACKNOWLEDGMENT}

This work is part of the BESQ+ research project funded by the Knowledge Foundation (grant: 20100311) in Sweden.

\section{REFERENCES}

[1] V. R. Basili, F. E. McGarry, R. Pajerski and M. V. Zelkowitz, "Lessons learned from 25 years of process improvement: the rise and fall of the NASA software engineering laboratory", Proc. International Conference on Software Engineering, pp. 69-79, 2002.

[2] K. Beckman, N. Coulter, S. Khajenoori and N. R. Mead, "Collaborations: closing the industry-academia gap", IEEE Software, Vol. 14, No. 6, pp. 49-57, 1997.

[3] G. Pour, M. L. Griss and M. Lutz, "The push to make software engineering respectable", IEEE Computer, Vol. 33. NO. 5, pp. $35-43,2000$.

[4] A. J. Kornecki, S. Khajenoori, D. Gluch and N. Kameli, "On a partnership between software industry and academia", Proc. $16^{\text {th }}$ International Conference on Software Engineering Education \& Training, pp. 60-69, 2003.

[5] C. Wohlin and B. Regnell, "Achieving industrial relevance in software engineering education", Proc. $12^{\text {th }}$ International Conference on Software Engineering Education \& Training, pp. 16-25, 1999.

[6] M. Staron, L. Kuzniarz and C. Wohlin, "Empirical assessment of using stereotypes to improve comprehension of UML models: a set of experiments", Journal of Systems and Software, Vol. 79, No. 5, pp. 727-742, 2006.

[7] L. G. Votta, A. Porter and D. Perry, "Experimental software engineering: a report on the state of the art", Proc. $17^{\text {th }}$ International Conference on Software Engineering, pp. 277, 1995.

[8] T. Gorschek, P. Garre, S. Larsson and C. Wohlin, "A model for technology transfer in practice", IEEE Software, Vol. 23, No. 6, pp. 88-95, 2006.

[9] C. Wohlin, A. Aurum, L. Angelis, L. Phillips, Y. Dittrich, T. Gorschek, H. Grahn, K. Henningsson, S. Kågström, G. Low, P. Rovegård, P. Tomaszewski, C. van Toorn and J. Winter, "Success factors powering industry-academia collaboration in software research", IEEE Software, Vol. 29, No. 2, pp. 67-73, 2012.

[10] P. Runeson, "It takes two to tango - an experience report on industry - academia collaboration", Proc. $5^{\text {th }}$ International Conference on Software Testing, Verification and Validation, pp. 872-877, 2012.

[11] A. R. Hevner, S. T. March, J. Park and S. Ram, "Design science in information systems research", MIS Quarterly, Vol. 28, No. 1, pp. 75-105.

[12] T. Gorschek and C. Wohlin, "Requirements abstraction model", Requirements Engineering Journal, Vol. 11, No. 1, pp. 79-101, 2006.

[13] T. Gorschek, P. Garre, S. Larsson and C. Wohlin, "Industry evaluation of the requirements abstraction model", Requirements Engineering Journal, Vol. 12, No. 3, pp. 163-190, 2007. 